\title{
Incredulidad moderna y cristianismo según Teilhard de Chardin
}

Este problema - su estudio y solución- centró sobre sí la vocación y las mejores energías de la existencia azarosa de Teilhard de Chardin. El conjunto de su vida presenta a este respecto un valor de testimonio excepcional. Sobre las elucubraciones más o menos afortunadas de los "teólogos de gabinete», Teilhard ofrece el factor decisivo de su experiencia vital y su reflexión continuada (sobre el terreno».

En efecto, la providencia y la arbitrariedad humana le situaron permanentemente en el frente de avanzada, en las fronteras de la $\mathrm{fe}$ cristiana, tanto local como espiritualmente:

"Sólo ofrezco un testimonio de mi vida, un testimonio que podría callarme, más soy una de las pocas personas que pueden darlo. Durante medio siglo cumplido ha mi suerte (mi fortuna) el haber podido vivir en un contacto profesional íntimo y estrecho - tanto en Europa como en Asia y en América- con lo que estos continentes contaban o cuentan todavía de más significativo, de más influyente, de más 'germinal' podría decirse, en materia de sustancia humana.

Pues bien, gracias a estos inesperados contactos excepcionales me ha sido permitido a mí, un jesuita (es decir, educado en el propio corazón de la Iglesia) penetrar y moverme como en mi casa en las zonas más activas del pensamiento y de la investigación libres, y era natural que algunas cosas, poco significativas para quienes sólo han vivido en uno de los dos mundos en presencia se me hayan aparecido con evidencia tan grande que me fuerzan a hablar" 1.

Esta experiencia existencial se refuerza por el hecho de que Teilhard mantuvo una visión idéntica del problema y sus implicaciones a lo largo de toda su vida. Hasta tal punto se hallaba persuadido de ella.

1. El Corazón del Problema (1949). PH, 322-3 / V, $340 /$. 
a) El diagnóstico: una forma nueva de religiosidad en conflicto con la fe cristiana.

Esta visión parece ya en los primeros escritos. Es el despertar de "la vida cósmica", la manifestación del Universo que adopta la forma y "la llamada de una Divinidad». Ha surgido (el Servicio de la Tierra), que asciende (del fondo de la Humanidad) como (una aspiración común». Como ante (una nueva luz», la masa humana se pone en movimiento y parte "como a la conquista de un nuevo Santo Grial...» Es la fuerza y el atractivo de "la Evolución», que se prolonga desde ahora en el espíritu hacia (un término absoluto" ".

Cuando poco después escribe su "manifiesto" para la (evangelización de los tiempos nuevos», vuelve a sentar una afirmación rotunda: "Existe, en nuestros días, voy a mostrarlo, un movimiento religioso natural muy poderoso', dentro del cual es preciso que los cristianos participen positivamente. Este (movimiento religioso profundo's se caracteriza

"por la aparición (en la conciencia humana) del Universo, percibido como un Todo natural más noble que el Hombre, y por tanto equivalente a un Dios (terminado o no) para el Hombre" ${ }^{3}$.

Eso sí, la "figura» de ese Dios es aún muy confusa. Propiamente, habría que decir que (es su aurora lo que vemos brillar», que surge del lado a donde se dirigen "la Vida, la Verdad, el Espíritu».

Este (ideal divino moderno) sucede a una ilusión (geo-antropo-europeo-céntrica). Hoy vemos desarrollarse ante nuestros ojos una nueva cosmovisión, centrada en el futuro del hombre. Todavía se nos manifiesta demasiado nebulosa para apreciar sus contornos. Por eso tampoco (sabemos darle un nombre preciso a ese gran Ser)" cuya presencia entrevemos.

Pero, (el hombre moderno sabe ya que no adorará una divinidad si ésta no posee ciertos atributos, en los cuales la reconocerá):

\footnotetext{
2. La Vida cósmica (1916) ETG, 27-38 / 9-8/. El dominio del mundo y el Relno de Dios (1916). Ib. $97-104 / 67-73 /$.

"Jesús, dulce como un Corazón ardiente como una Fuerza, íntimo como una Vida, Jesús en quien puedo fundirme, con quien he de dominar y liberarme, os amo como un Mundo, como el Mundo que me ha seducido, y sois Vos, lo veo ahora, a quien los hombres, mis hermanos, incluso aquéllos que no creen, sienten y buscan a través de la magia del inmenso Cosmos". ETG, 89-90/59-60/.

3. Nota para servir a la Evangelización de los tiempos nuevos (1919), en ETG, 367-9. Este opúsculo, incomprensiblemente, ha sido omitido en la versión española.
} 
"El Dios que nuestro siglo espera debe ser:

$1 .^{\circ} \tan$ Vasto y misterioso como el Cosmo.

2. $\quad$ tan inmediato y envolvente como la Vida.

$3 .^{\circ}$ tan ligado (del modo que sea) a nuestro esfuerzo como la Humanidad.

Un Dios que nos hiciese el Mundo más claro, o más pequeño, o menos interesante de lo que lo descubren nuestro corazón y nuestra razón, ese Dios - menos hermoso del que nosotros esperamos no será jamás aquél ante el que la Tierra se arrodi$11{ }^{\prime \prime}{ }^{4}$.

En marzo de 1929 terminó Teilhard El sentido humano. Es un ensayo escrito con gran franqueza, que señala un reajuste importante en su cosmovisión : el (sentido humano» sustituye, en gran parte, al (sentido cósmico). Teilhard saluda con alborozo el (despertar del sentido humano) en el mundo moderno (él mismo acababa de descubrirlo), esto es, "la conciencia tomada por el pensamiento terrestre de constituir un Todo organizado, dotado de crecimiento, capaz y responsable de un porveniry.

Ello significa un cambio de dirección en la antropogénesis: ha concluido la vía de la individuación y se abre paso lentamente la vía de la (solidaridad). Individualmente el hombre ha alcanzado su máximo: el crecimiento se realizará en adelante por medio del "sentido humano». Se trata de un verdadero cambio "cualitativo», por la acción convergente y sumultánea de varios factores: descubrimiento de la evolución, desarrollo de las ciencias físicas y naturales y, sobre todo, el influjo siempre creciente de las ciencias sociales, que han despertado un inmenso movimiento de solidaridad y la conciencia de formar una humanidad.

Por tanto, la "fe en el mundo» se va a expresar a través de la (fe en el hombre). Desde hace unos I5o años, tras la adolescencia del renacimiento y la ilustración, el hombre ha devenido adulto y ha tomado conciencia de sí mismo. De (espectador) del mundo se ha

4. lb., 369-370. El último párrafo figura enteramente subrayado en el original.

Es lo que Teilhard llama "el cisma de la carldad". A comienzos de 1918 escribia con cierto patetismo: "Quienquiera que en nuestros dias haya frecuentado a los incrédulos de otra manera que en un manual escolar; quienquiera, quiero decir, que haya encontrado, bien en la lectura simpática de sus escritos, bien en el trato de su amistad, el sentido de sus aspiraciones profundas, estará de acuerdo conmigo en que se halla, en los mejores de nuestra raza, un cierto temor de que el cristianismo no sea suficientemente bello para los deseos de su corazón. En la medida en que somos capaces de leer en otras almas, cuando la nuestra nos está a veces medio cerrada, hay entre nosotros hombres sinceros y religiosos, hombres que viven en el esfuerzo y se hallan dispuestos a la propia renuncia, que no encuentran nuestros dogmas a la medida de sus anhelos. En ellos no está muerta la caridad (natural); tampoco se puede decir que se halla en trance de enfriamiento: camina a su manera hacia una cierta Realidad más pura, más humana, más elevada; hacia un 'Anticristo' apasionadamente amado...". ETG, 268 / $222 /$. 
convertido en (constructor). El descubrimiento de la evolución ha sido fundamental para despertar un nuevo sentido de la acción, la responsabilidad y las aspiraciones humanas. Los hombres buscan entregarse a "una gran obra que los supera).

¿Qué significa esto? “Un poderoso fenómeno de orden religioso). La conquista del futuro es una Fe y exige una Renuncia: son los dos atributos de toda adoración. Pero, en realidad, significa mucho más que el surgir de una nueva religión : es la transformación y unificación de todo el poder religioso de la tierra. Es la única religión ya posible, "la que permita al hombre, ante todo, amar y servir apasionadamente al Universo"). Es un acuerdo total de la Vida consigo misma : "la Humanidad destruirá el Universo sino lo puede adorar). De aquí la necesaria trasposición que hay que verificar de los valores cristianos de acuerdo con las nuevas dimensiones que impone este (sentido humano»" .

El mismo diagnóstico se concretará conforme se desarrolle paralelamente su visión del fenómeno humano y de la gestación del ultrahumano socializado. Por encima de nuestra (crisis moral", "la fase actual de la historia terrestre) se caracteriza por una aspiración hacia algún «Absoluto»:

\begin{abstract}
"/.../: el despertar del Sentido humano. Positivamente, los hombres empiezan a sentirse ligados, todos juntos, a una gran tarea, cuyo progreso les cautiva casi religiosamente. Saber más, poder más. Estas palabras, aun cuando para muchos tengan un sentido utilitario, se aureolan, para casi todos, de un prestigio casi sacro" ${ }^{6}$.
\end{abstract}

Teilhard no está de acuerdo con los que caracterizan como (materialista) la civilización occidental. Es cierto que (eel Occidente ha derribado muchos ídolos. Pero, por medio de su descubrimiento de las dimensiones y de la marcha hacia adelante del Universo, ha puesto en movimiento una Mística poderosa. Porque se trata propiamente de una Mística (...)). Toda la cuestión consiste ahora en (determinar la verdad y el nombre de la Presencia que creemos sentir tras el Univer. so inflamado", "descubrir los rasgos del Mesías que esperamos».

Es cierto que han caído muhas "cascarillas del grano", pero ello no significa que (la necesidad de Absoluto se haya disipado»:

5. El sentido humano (1929). Inédito.

6. El Fenómeno humano (1930). VP, $215 / \mathrm{III}, 241 /$ 
"Como un retoño del que se han desprendido las escamas, el núcleo religioso, en el que está concentrado lo mejor de la savia humana, aparece en este mismo momento ante nuestros ojos, más diferenciado y vigoroso que nunca" 7 .

Poco después Teilhard precisa que se refiere a "los panteismos humanitarios), en los que ve (una forma enteramente joven de religión». Una religión ciertamente extraña, (poco o nada codificada (a excepción del Marxismo)", aparentemente (sin Dios y sin revelación. Pero Religión en la verdadera acepción de la palabra, si por ella se designa la fe contagiosa en un Ideal por el que dar la propia vida). Así "bajo formas variables (comunistas o nacionalsocialistas, científicas o políticas, individuales o colectivas) asistimos positivamente al nacimiento y a la constitución en torno a nosotros, de un siglo a esta parte, de una Fe nueva: la Religión de la Evolución) ${ }^{8}$.

Lo que ocurre entonces es que «el Mundo se está convirtiendo espontáneamente a una especie de Religión natural del Universo que le desvía indebidamente del Dios del Evangelio: en eso consiste su incredulidad). Pero bastará con que el Cristianismo desarrolle su virtualidad animadora de la cosmogénesis para que «de la prolongación misma de lo que constituye la incredulidad de hoy, salga quizá la fe de mañana" " ?

El diagnóstico se confirma ante el desastre general de la segunda guerra mundial: es una (crisis de metamorfosis y de crecimiento» en todos los órdenes y especialmente en el religioso. Ahora, más que nun-

\footnotetext{
7. El cristianismo en el mundo (1933). CC, 121-5 / IX, 131-6/.

8. Cómo creo yo (1934). CYC, 134-5/X, 143-4/.

"No, lo sé: no es por cuestión de palabras por lo que mis Ensayos han sido siempre descartados (como sospechosos de panteismo). Es porque mis censores han comprendido, con razón, que para mi todo el Universo (comprendidas las relaciones entre lo Divino y lo participado, lo Natural y lo Sobrenatural) eran de naturaleza orgánica (o genética, no simplemente jurídica). Para los 'oficiales', en este momento, el Universo está infravalorado, a causa de una concepción equivocada de la 'contigencia de la creación'. Los 'oficiales' (se lo repito, me lo han dicho con toda claridad en Roma, en 1948) no creen en un Futuro de lo Humano (fuera de una $\mathrm{Pa}$ rusía de catástrofe)". Carta a C. Tresmontant, inédita, 8 febrero 1954.

9. La incredulidad moderna (1933). CC, $141 / \mathrm{IX}, 153$ /. Los subrayados son míos.

Compárese con este texto: "Igualmente, la llamada de Nietzsche: 'Hermanos, permaneced fieles a la Tierra' está más en contradicción con un platonismo cristiano que con la fe cristiana misma, que constituye justamente una nueva esperanza para este mundo terrestre de un ardor mucho más fuerte que el mostrado por el marxismo. En su calidad de epigono, el marxismo no aporta más que un sustituto de la esperanza cristiana; o, más exactamente, habiendo nacido de la deteriorización de esta esperanza, el marxismo está teñido él mismo de resignación, como tendremos ocasión de mostrar. La esperanza cristiana es mucho más radical y más vasta: nace de la promesa de que la creación llegará a su término, que todo lo que la destruye será superado y abolido; es decir, no solamente el mal, sino también la muerte y, mejor aún, la muerte en nosotros, el pecado en sus raíces más profundas. En efecto, esta esperanza no lleva al retorno a un paraíso perdido, sino a 'un cielo nuevo y a una tierra nueva'". H. GOLLWITZER, Athéisme marxiste foi chrétienne. Casterman, París 1965, 128. Es la misma tesis de J. Moltmann.
} 
ca, la humanidad (cestá presta a recibir un Salvador). Esta es (la palabra esperada) ${ }^{10}$.

La situación permanece invariable al final de la contienda. No se trata de ningún (enfriamiento» religioso. ("En realidad, jamás estuvo tan ardiente). Lo que sucede es que el hombre actual se hace progresivamente consciente de su compromiso con la antropogénesis. De (cesta toma de conciencia) se derivan-informes pero poderosas-aspiraciones y esperanzas sin límite. Sobre los ruidos discordantes sube una nota fundamental única, a saber, la fe y la esperanza en alguna salvación vinculada al acabamiento evolutivo de la Tierra:

"No, el Mundo moderno no es irreligioso, sino muy al contrario. En él ocurre sencillamente que, por brusco aflujo, en dosis masiva, de una savia nueva, el espiritu religioso, en su totalidad y en su misma trama, se agita y se transforma" 11.

Teilhard concretará todavía más su diagnóstico al examinar lo que llama (el corazón del problema). Es indudable el hecho de una (insatisfacción generalizada) en nuestro mundo actual. Mientras, los diversos (credos) religiosos parecen hallarse estabilizados o en clara regresión. "No es que el mundo se esté enfriando: ipsíquicamente jamás estuvo más ardiente!». Sin embargo, "por alguna oscura razón hay algo que 'no marcha' en nuestro tiempo entre el hombre y Dios, tal como Dios se le presenta al Hombre hoy. 'Todo acontece hoy día como si el Hombre no tuviera exactamente ante sí la figura del Dios que desea adorar». De ahí (esta impresión obsesionante, por todas partes, de un ateísmo que asciende irresistiblemente» y de una simultánea "descristianización ascendente e irresistible» ${ }^{12}$.

Pero advierte en seguida que hay que considerar con detención

10. La palabra esperada (1940), Cahiers 4, 22-3.

Sobre el actual planteamiento del probiema de Dios habia escrito en 1936: "Ahora, el problema de Dios se ofrece a la acción humana total, y sólo puede abordarse por el esfuerzo total de la búsqueda y de la experiencia humana. No sólo Dios da un valor para siempre al esfuerzo humano, sino, además, su revelación es una respuesta a la totalidad del esfuerzo humano". CV, $209 / \mathrm{LV}, 207 /$.

11. Cristianismo y evolución (1945). CYC, 192-3 / X, 204-5/.

12. Uno de los aspectos más inquietantes del Mundo actual es la generalizada insatisfacción que en él se manifiesta y de un modo además creciente, por lo que atañe a la religión. En este momento no hay huella alguna (salvo bajo una forma humanitaria que hemos de discutir más tarde). no hay huella alguna sobre la Tierra de una fe en estado de exapansión; tan sólo aquí $y$ allí diversos Credos prácticamente estabilizados, cuando no se hallan en vías de clara regresión. No es que el Mundo se esté enfriando: psíquicamente jamás estuvo más ardiente! No es que el Cristianismo haya perdido nada (todo lo contrario) de su capacidad de seducción absoluta: cuanto aquí voy a decir no tiende más que a probar su extraordinario poder de adaptabilidad y de control. Más he aquí: indudablemente, por alguna oscura razón, hay algo que 'no marcha' en nuestro tiempo entre el hombre y Dios, tal como Dios se le presenta al Hombre hoy. Todo acontece hoy día como si el Hombre no tuviera exactamente ante sí la figura del Dios que desea adorar... De aquí, en conjunto ( $y$ a pesar de ciertos síntomas decisivos de 
las específicas circunstancias del fenómeno. Teilhard ofrece su testimonio personal y su continuada reflexión sobre el problema. Hay que tener en cuenta, ante todo el "gran acontecimiento» que domina en la conciencia de la humanidad actual: la gestación de lo "Ultrahumano»: (se está formando el Hombre). Esta conciencia se concreta en un ideal supremo: podemos y debemos construir nuestro futuro. De este modo, la aspiración tradicionalmente (trascendente) (hacia lo Alto) se ha curvado (hacia Adelante»,

Aquí se enraiza el malentendido fundamental, (cel corazón del problema). Porque dichos movimientos aparecen como incompatibles, cuando en realidad deberian ser convergentes. Teilhard no duda en identificar ambas corrientes con el humanismo marxista (que encarna el (hacia adelante») y la fe cristiana ((hacia arriba»). En realidad, la convergencia se realiza espontánemente, según ha podido comprobarlo:

"por todas las conversaciones que he podido sostener a lo largo de mi vida con intelectuales comunistas, tengo la impresión de que el ateísmo marxista no es absoluto, sino que rechaza tan sólo una forma de Dios, 'tipo extrínseco', rechaza a un Dios 'ex-machina', cuya existencia rebajaría la dignidad del Universo y distendería los resortes del esfuerzo humano: un 'Pseudo-Dios', en definitiva, que nadie desea (empezando por los cristianos) en el día de hoy" ${ }^{13}$.

Hasta última hora, Teilhard reafirma su convicción -mitad testimonio personal, mitad razonamiento- de que el sentimiento religioso tiene que hallarse en aumento, como corresponde a la etapa evolutiva que atravesamos: la religión está llamada a ser el gran estimulante y animadora del esfuerzo evolutivo ${ }^{14}$.

renacimiento, pero todavia subterráneos), esta impresión obsesionante, por todas partes en torno a nosotros, de un ateísmo que asciende irresistiblemente, o todavía más específicamente, de una descristianización ascendente e irresistible".

$\mathrm{PH}, 321-2 / \mathrm{V}, 339 /$.

13. Ib., 323-9 /V, 340-6/. Sobre el humanismo marxista hacía esta observación: "Observemos que se trata de una simplificación peyorativa en lo que concierne a ox / fe hacia adelante/, en la medida en que marxismo y comunismo (muy mala palabra, y muy mal escogida, digámoslo de paso) no son manifiestamente más que la forma embrionaria, o incluso caricaturizada, de un Neohumanismo todavía balbuciente". PH., 326, nota / V, $339 /$.

No obstante. Teilhard reconocia también sus valores. No le gustaba que, como en el caso de Gusdorf, se le redujera a una búsqueda de "bien-estar", cuando se trata de "la sed de un más-ser". Y no sólo tiene "el sentido de la Justicia", sino también "el sentido de lo Evolutivo". Carta a C. Cuénot, inédita, 25 abril 1954.

En realidad. Teilhard estuvo más en contacto con otra modalidad del ateísmo, el humanismo cientifico, en el que encontraba igualmente un dinamismo de trascendencia: "/.. los materialistas actuales no son en definitiva (como tan frecuentemente he tenido la impresión al escucharles 0 al leerles) sino 'espiritualistas' que se ignoran". AE, 379 /VII, $425 /$.

14. Es ésta una de sus ideas dominantes. Véase, por ejemplo, AE, 373-382 / VII, 417-429/. 
En Cómo creo yo había escrito:

"Próximo está el día en que la Humanidad, en virtud de su posición en una Evolución cósmica cuyo descubrimiento y crítica ha sido capaz de realizar, advertirá que está biológicamente emplazada entre el suicidio o la adoración" ${ }^{15}$.

Lo que ocurre es que "todavía no ha encontrado un Dios a quien poder adorar) ${ }^{16}$.

Ahora bien, lo grave es que "la incredulidad moderna", esta nueva forma de religiosidad, adopta una forma (anticristiana), más o menos marcada según los casos.

También el cristianismo, por su parte, se ha enfrentado de diversos modos -ignorancia, restricciones, condena - con el nuevo humanismo. El desarrollo cristiano pretende desenvolverse en total divorcio con "el Progreso humano». Lo más grave es que, con el enfrentamiento, la fe cristiana llegó a olvidar determinadas virtualidades y dimensiones propias, que ahora no podrá recuperar más que por medio de una conjunción con el espíritu moderno: el Cristo cósmico, el valor objetivo del esfuerzo humano, el espíritu de investigación, etc.

En diversas ocasiones ha trazado Teilhard de Chardin un cuadro histórico -apresurado, pero certero- de la oposición y el choque Iglesia-Mundo. El origen hay que buscarlo en el Renacimiento. Tras la época medieval, en la que se había confundido la tierra con el cielo, surge (cel impulso autónomo de las aspiraciones naturales), el legítimo estatuto de los valores seculares, que adoptó desde el primer momento el carácter de una reivindicación. La Iglesia tampoco supo reconocerlo a tiempo. Ello provocó la mutuas (injurias) y el choque abierto y declarado. Desde entonces "las dos partes de la Verdad se han estrellado», al buscar (reglamentar la conducta de los hombres cada una por su cuenta). El Naturalismo y el Laicismo fueron las consecuencias. Por su parte, la Iglesia "anatematizó el Siglo y pareció que tenía por diabólica la tarea del Progreso». Desde entonces también «ambos poderes sufren cruelmente las consecuencias del aislamiento) ${ }^{17}$.

\footnotetext{
15. CYC, $117-8 / \mathrm{X}, 133 /$.

16. Carta de 10 diciembre 1952 (cit. por C. Cuénot, o. c. 515)

En 1931 se expresaba en parecidos términos: "IEI mundo necesita un Dios! |EI mundo necesita un Dios! Pero que nuestra idea de Dios crezca hasta abarcar las dimensiones de nuestro Mundo..." CV, $144 / \mathrm{LV}, 136 /$.

17. ETG, 109-112 /77-79/; CC, 138-9 / IX, 150-151/. Un notable psicólogo de la religiosidad, A. Vergote, hace un diagnóstico muy similar: "En los tiempos modernos el hombre ha
} 
Este ha sido el gran escándalo de los pasados siglos: el hecho de que "cristiano" y (humano" hayan tendido a no coincidir. El cisma es realmente vergonzoso. $\mathrm{Y}$ a la Iglesia corresponde el deber de rectificar la primera, para que pueda cumplir su función salvadora ${ }^{18}$.

Porque lo cierto es que (este Mundo hubiera podido formarse y crecer siendo creyente. ¿Cuál es la razón de su emancipación? ¿Por qué intenta el niño pegar a su madre?) Porque el cristianismo "no les parece lo suficientemente hermoso", porque "les parece invenciblemente inhumano e inferior), porque los cristianos dan la impresión de ser (desertores y falsos hermanos»" ${ }^{19}$. Examinemos, pues, detenidamente las causas que han podido favorecer este inmenso y deplorable malentendido.

b) Las razones de la incredulidad moderna.

Las (formas y raíces del ateísmo") que el Vaticano II ha señalado, parecen estar directamente inspiradas en Teilhard de Chardin. Al menos existe una coincidencia casi total. Ambos aseguran que el fenómeno ateo, "considerado en su total integridad, no es un fenómeno originario, sino derivado de varias causas». Entre éstas se cuentan «la reacción critica contra las religiones», especialmente - (en algunas zonas del mundo»- (contra la religión cristiana». También se destaca (en la génesis del ateísmo» la parte que corresponde al «descuido

adquirido una conciencia más aguda de su libertad, no solamente en un retorno reflejo sobre si mismo sino en la afirmación del mundo humano que está en trance de construir. El dominio técnico sobre la naturaleza y la conciencia de la dimensión histórica del mundo humano, tienen por resultado el identificar más que nunca al hombre con su acción, y hacerle cada vez más difícil el concebir el perfeccionamiento de la condición humana en una línea propiamente religiosa. La integración de los valores terrestres en la actitud religiosa ha llegado a ser para los creyentes ui probiema crucial. Para el hombre contemporáneo, la máxima evangélica que invita a perder la vida para ganarla parece significar que la divinización del hombre en la relación con Dios no puede obtenerse más que por la renuncia de su condición propiamente humana; pero, al mismo tiempo, el creyente guarda la convicción de que el Creador del mundo no puede ser un Dios malo y envidioso, dedicado a la destrucción de su propia obra.

En este horizonte asimétrico entre las tareas terrestres y su integración religiosa es donde el conflicto entre la voluntad de autonomia y el asentimiento, adquiere toda su amplitud. Entre los dos no puede haber ni coincidencia ni exterioridad. La religión debe englobar los valores terrestres, sin por ello absorberlos, y el compromiso humano debe ser la puesta en práctica de la actitud religiosa, sin jamás agotarla /.../ el ateísmo es, esencialmente, el estallido de esta polaridad asimétrica entre lo terrestre y lo religioso". A. VERGOTE, Psicología rellgiosa, Taurus, Madrid 1969, 312-3.

18. ETG 371-2. "no nos engañemos. El ideal cristlano (tal como se expone de ordinario) ha dejado de ser. - como nos pavoneamos siempre, un poco beatamente- el Ideal común de la Humanidad. Si han de ser sinceros, cada vez serán más los hombres que confesarán al predicador que el Cristianismo les parece invenciblemente inhumano e inferior, tanto en sus promesas de felicidad individual como en sus máximas de renunciamiento. "Vuestro Evangelio, dicen ya, tiende a formar almas interesadas en sus ventajas egoístas, desinteresadas del trabajo común: por tanto, no es interesante para nosotros". Ib., 370. Nótese que escribe en 1919.

19. ib., lb.; CC, 144-5/IX, 158-9/. Es la terrible acusación que recoge en El Medio divino: "El cristianismo crea desertores y falsos hermanos: he aquí 10 que no podemos perdonarle". MD, 58 / IV, 60 /. 
de la educación religiosa) y a la "exposición inadecuada de la doctrina», además de "los defectos de su vida religiosa, moral y social», que "han velado más bien que revelado el genuino rostro de Dios y de la religión ${ }^{20}$.

Acabo de exponer los testimonios de Teilhard al respecto. Si los reducimos a sistema, obtenemos las siguientes proposiciones:

\section{r. Existe un "cisma ilegítimo» entre el Cristianismo y la "corriente religiosa natural humana).}

Tal fue el testimonio presentado por Teilhard como respuesta a una encuesta "sobre las razones actuales de la incredulidad». Teilhard no vacila en calificarla (la fuente primera). Por cierto que considera ( $\tan$ generalizado» el ateísmo en el campo intelectual que en ocasiones "los creyentes constituyen una excepción). Sin embargo, ya lo hemos visto, añade que no cree que nuestro tiempo sea (cradicalmente incrédulo o arreligioso). Lo que sucede es que, a causa del mencionado "cisma ilegítimo», su (facultad natural de adoración ha derivado

20. Constitución Gaudium Spes, n.0 20, Los subrayados son mios.

Véase este valiente alegato de $\mathrm{H}$. Gollwitzer: "Ante todo, importa renunciar a la indignación, tan extendida hoy en los medios eclesiásticos, de los que ven en el ateísmo una invención maligna y enteramente nueva de los comunistas. El único elemento nuevo que aporta el comunismo es el tomar en serio el ateísmo, mientras que la Iglesia debe, desde hace mucho tiempo, su posición social al hecho de que, aunque el mundo sea ateo a su alrededor, no ha podido, sin embargo, hasta hoy sobrepasar el decoro cristiano (...). Ahora, no obstante, se han sacado las consecuencias del viejo ateísmo de los naturalistas, historiadores, psicólogos y sociólogos, del materialismo de la economía capitalista, de la falta de influencia del cristianismo sobre la producción, el comercio y la política, de la esquizofrénica división del hombre en pagano de la semana y cristiano del domingo, de la falta de realización de las doctrinas sociales cristianas (...).

Asi se desploma el sentimiento de seguridad de la Iglesia, que se había nutrido hasta ahora de la convicción de que las costumbres cristianas estaban sólidamente ancladas en el pueblo y que el cristianismo era estimado, al menos como factor cultural y espiritual, por lo no-practicantes, y que, por estas razones, mantenía sus pretensiones al respeto y a los privilegios. Pero el comunismo no respeta las cosas que no tienen otro título que su existencia; las considera ya pertenecientes al pasado y no está dispuesto a permitirle proseguir su existencia más que mediante la prueba dialéctica.

Este planteamiento radical e irrespetuoso provoca en la Iglesia sentimientos de horror y de indignación. Opera ahi una reacción del cuerpo carnal de la Iglesia (en términos marxistas: una forma de lucha de clases). Al contrario, la reacción espiritual implica que la lglesia no sólo lo admite porque es preciso, sino que acepta interiormente este hecho: que el cristianismo ha dejado ya de ser un tabú hoy, sino que provoca discusiones encarnizadas, y que ni su prestigio ni su influencia van ya a imponerse sin más.

La Iglesia debe admitir no ser ya en adelante admitida sin reservas por el mundo. Rehusando hacerlo, el mundo vuelve a tomar en serio a la Iglesia o, al menos, deja entrever que la considerará de nuevo bajo ese ángulo. La Iglesia no puede admitir interiormente esta situación más que interpretando las graves cuestiones que le propone el mundo como una interpelación de Dios, como la interrogación de su propio Señor que le otorga la gracia de sus avisos para ayudarla a proseguir su existencia. Desgraciadamente, no puede afirmarse que una tal reacción espiritual sea ya reconocida verdaderamente en los medios cristianos. Lo que aparece en las declaraciones oficiales, los sermones y la prensa eclesiástica de las diversas confesiones es únicamente la reacción impenitente del cuerpo carnal de la Iglesia...". H. GOLLWITZER, op. sit. 179-181.

El original alemán es anterior al Concilio. Pero, ¿cambia eso las cosas en algo? 
hacia un Objeto, el Universo, que le parece estar en oposición con el Dios (ristiano) ${ }^{21}$.

A partir del Renacimiento, se ha operado un cambio revolucionario en nuestra concepción del Universo y del Hombre. Por vía experimental como reflexiva "hemos cobrado conciencia de la grandeza unitaria del Cosmos y de la significación orgánica del Tiempo") (Evolución). Desde hace siglo y medio, especialmente, el hombre se ha hecho progresivamente consciente de su papel en la cosmogénesis y ha asumido su responsabilidad. Como es natural, esta nueva perspectiva (rrepercutía de hecho hasta en las profundidades religiosas del alma).

Por otra parte, paralelamente, se forjaba de modo espontáneo (una especie de Religión del Mundo, confusa en sus dogmas, pero perfectamente clara en sus orientaciones naturales): predominio del Todo sobre el individuo, fe apasionada en el valor y las posibilidades del esfuerzo humano, percepción del "carácter sagrado de la investigación». Todo ello converge en una situación fundamental: (el Hombre moderno no puede reconocer ya a Dios más que en prolongación (¿podríamos decir quizá : bajo las especies?) de cierto progreso o maduración universal)».

Ahora bien, el cristianismo ha dado (ciertamente la impresión de haberse librado, e incluso de oponerse a la 'revolución' psicológica que acabamos de analizars:

\begin{abstract}
"No se decide a aceptar francamente, en su generalidad y en su espiritu, las perspectivas (universalmente admitidas fuera de él) del desarrollo cósmico. Parece complacerse en minimizar las esperanzas humanas y en destacar las debilidades de nuestra sociedad. Siente desprecio o temor por el progreso o el descubrimiento. No aporta, en suma, ninguna consagración ni engrandecimiento a las aspiraciones más elevadas y más hondamente sentidas del Hombre de hoy".
\end{abstract}

Tal es (la apariencia) que la fe cristiana presenta al exterior y ello es (terriblemente decepcionante para quienes nos observan desde fuera). Y lo lamentable es que el Cristianismo, en su esencia y en su espíritu más auténtico, no sólo no tiene por qué oponerse a las aspiraciones del hombre moderno, sino que positivamente las incluye y

21. La incredulidad moderna (1933). CC, $137 / \mathrm{IX}, 149 /$. Se trata de una respuesta a la encuesta realizada por La Vie Intellectuelle sobre las causas de la incredulidad moderna. 
engrandece en el corazón mismo de su mensaje. No se trata, pues, de que "los dogmas sean demasiado elevados y su moral demasiado difícil». Lo que sucede realmente es que «los Hombres, al no reconocer ya en nosotros su ideal religioso y moral, se alejan, en espera de algo mejor) ${ }^{22}$.

De esta falta de sintonía con la corriente religiosa natural del mundo actual se sigue el fenómeno de (velar más bien que revelar el genuino rostro de Dios), que denunciaba el Concilio. Por eso, el hombre de nuestro tiempo tiene derecho a esperar de la Iglesia de Dios (cuna generalización y una profundización del sentido de la Cruz). Tampoco el creyente cristiano tiene por qué seguir sufriendo de cesquizofrenia religiosa), al no coincidir su creencia espontánea con la dirección de su fe cristiana. La Cruz no es sólo (signo de expiación), sino también de (evolución, esfuerzo, progreso). No es la sombra lo más importante de la Cruz, sino su luz ${ }^{23}$.

El hombre de nuestro tiempo, creyente o no, necesita imperiosamente sentir el gusto y la justificación de su esfuerzo por una humanidad mejor a todos los niveles. Instintivamente los busca en iu fe religiosa. Precisa no solamente una religión de trascendencia, sino una religión energéticamente impulsora y activadora del esfuerzo humano. Por eso, el hombre actual se entregará a la fe religiosa que excite al máximo su poder de autoelevación ${ }^{24}$.

El Dios cristiano debe adoptar la figura del (Dios de la Evolución) para conseguir atraer a nuestros contemporáneos. Para satisfacer su sentimiento religioso natural, debe mostrarles «lo divino en la Evolución). La creación, lejos de ser un acto instantáneo y puramente gratuito, se convierte en la (creación evolutiva), que incluye la libre colaboración humana, que se prosigue hasta su definitiva incorporación a Cristo-Omega ${ }^{25}$.

\footnotetext{
22. CC. 138-9/IX. 150-152/. A propósito del paso del P. Tongi, S. J., de la Gregoriana al Comunismo, comentaba Teilhard: es preferible no hablar de "infiltraciones del comunismo", sino tratar de "vacunar" a los cristianos contra el marxismo presentándoles el Dios hacia Arriba-Adelante. De lo contrario, las defecciones se multiplicarán. Carta a J. Mortier, inédita, 30 abril 1952.

Lo mismo decía respecto de los sacerdotes-obreros: "si los sacerdotes-obreros no resisten al marxismo, ¿no es acaso porque se encuentran cara a cara con un 'humano' más fuerte que el suyo (no sólo un sentido de la justicia social, sino sentido de un porvenir)?". Carta a C. Tresmontant, inédita, 8 febrero 1954.

23. CYC, 235-243/X, 251-261\%.

24. "Tarde o temprano, las almas terminarán por entregarse a la Religión que las active más humanamente". CYC, 245-253 / X, 265-272 /.

25. Ib., $263-270 / X, 285-291 /$.
} 
2." "Raíces profundas de la crisis: un nuevo sol se levanta».

Un segundo factor, de excepcional importancia, viene a conjugarse con el precedente: el atractivo idolátrico que el universo, en sus nuevas dimensiones, ofrece a los hombres de nuestro tiempo. Un atractivo que les fascina y les oculta toda orientación trascendente ${ }^{26}$.

En efecto, "hasta la aurora de los tiempos modernos» la vida humana se situaba como un problema entre dos términos: la existencia temporal y “los fines últimos». Pero, desde hace doscientos años, por una serie de descubrimientos e iluminaciones, el hombre ha tomado conciencia de sus increíbles recursos y posibilidades con relación a su futuro. Por eso ahora, por encima del hombre, ya no se sitúa inmediatamente Dios, sino "una grandeza intercalar), un nuevo objeto (adorable» y más grande que él: es la Tierra y la Humanidad del futuro, "un nuevo astro que atrae sobre sí las potencias religiosas del Mundo». Es el nuevo "gran Mito") o, si se prefiere, "la tentación sobre la Montaña». Y como consecuencia, "el sentido de la Tierra" que suplanta en las conciencias la llamada de la "Caridad» ${ }^{27}$.

Aquí se presenta un grave problema de adaptación para la fe cristiana. Es ilusorio pretender que la humanidad camine "hacia atrás». El único camino posible para (convertir») al mundo, es decir, para apartar de su horizonte el objeto (pseudo-divino» que le absorbe, es el encarnarse en las corrientes de influjo de (la nueva estrella). Porque, en adelante, se trata de equilibrar (también en los creyentes cristianos) (no ya dos, sino tres Realidades en presencia: nuestro yo, Dios y el Porvenir terrestre del Mundo ante nosotros). Ignorar o minimizar el valor de este tercer factor sería tanto como condenarnos al fracaso ${ }^{28}$.

26. Teilhard ha descrito magnificamente en términos poéticos-biográficos, esta fascinación del cosmos en su primer escrito, bajo el epigrafe "la comunión con la Tierra". ETG, 39-44/ Ecrits, $19-23 \%$

27. La palabra esperada (1940), Cahiers 4, 24

Compárese con el famoso texto de Nietzsche: "¡Yo os conjuro, hermanos míos, a que permanezcáis fieles al sentido de la tierra y no prestéis fe a los que os hablan de esperanzas ultraterrenas! /.../ Son despreciadores de la tierra, moribundos y envenenados, para quienes la tierra es fatigosa: ipor eso quieren dejarla!

En otro tiempo, los crímenes contra Dios eran los más grandes crímenes; pero Dios ha muerto, y con él han desaparecido estos delitos. Ahora el crimen más terrible es el crimen contra la tierra, y poner por encima del sentido de la tierra las entrañas de lo incognoscible. En otro tiempo el alma miraba al cuerpo con desprecio, y este desprecio era entonces la virtud más excelsa: quería verle demacrado, horrible, muerto de hambre. Así creía poder emanciparse de él y de la tierra" (Asi habló Zaratustra).

28. Ib., 25. En noviembre de 1947 escribía Teilhard a E. Mounier: "Cuando se habla de una 'teología de la Ciencia moderna', esto no quiere decir evidentemente que la ciencia pueda determinar por sí sola una figura de Dios y una religión. Significa, si no me equivoco que dado un determinado desarrollo de la Ciencia, ciertas representaciones de Dios y ciertas formas de adoración quedan excluídas porque no son homogéneas con las dimensiones espirituales del Universo. 
Es esencial advertir los nuevos términos con que "se plantea hoy el problema de la conversión del Mundo». No se trata ya de (conquistar y de transformar un Mundo que terminaba) (decadencia del Imperio romano), ni de (organizar el Mundo de la civilización europea, nacido de él). A partir del Renacimiento ha nacido (un nuevo empuje humano", que no se ha desarrollado ya (bajo su signo». En efecto, tras el mundo grecorromano y el mundo medieval, ha surgido (el mundo moderno" que ha crecido (al margen del Cristianismo") y ("con un potencial humano más fuerte que el de éste». De hecho, a él se deben "todas las iniciativas recientes de la Tierra». No se trata ya de una herejía o un cisma, "ni siquiera de paganismos". Ante nosotros tenemos ahora (una corriente humana naciente), que se mueve en dos nuevas dimensiones: Universalismo y Futurismo», con una nueva religión también naciente. Por eso el conflicto actual ocurre entre dos clases de creyentes: (una Religión de la Tierra contra la Keligión del cielo) ${ }^{29}$.

3." "En la fuente de la crisis religiosa moderna: un conflicto de entre lo Hacia lo Alto y lo Hacia Adelante».

Ya hemos visto cómo para Teilhard el descubrimiento del Universo fue concretándose a partir de 1925 hasta adoptar la figura de lo "Ultrahumano» socializado. Este es (el gran acontecimiento en la conciencia humana” moderna. La Cosmogénesis despliega en su núcleo central una Antropogénesis. Naturalmente, de modo paralelo ha cambiado también la figura del universo y de la humanidad, con las correlativas derivaciones en lo religioso. La principal es ésta : la (super-vida) no se busca ahora primariamente "hacia lo Alto (eje Oy en dirección a lo Trascendente) sino más bien "hacia Adelante) (eje $\mathrm{Ox}$, en prolongación de las fuerzas inmanentes de Evolución).

En consecuencia, en todo ser humano «moderno» se produce espontáneamente un (estado de tensión), ya que, (een su propio corazón, junto a las tradicionales fuerzas ascensionales de adoración) con-

\footnotetext{
Esta noción de homogeneidad es ciertamente capital para la vida intelectual, moral y mística. Si los diversos escalones de nuestra vida interior no se definen rigurosamente los unos a los otros, en revancha tendrán que armonizarse en escala, en valor y en tonalidad. Porque de lo contrario, seria imposible realizar en nosotros una verdadera unidad espiritual, lo cual constituye quizá la exigencia más legítima, más imperiosa y más definitiva del Hombre de hoy y del Hombre de mañana".

Las "grandes modificaciones" de nuestra cosmovisión las resumla en estas tres: "organicidad total del Universo", "atomicidad" del mismo y "función primordiał de la Ordenación (o Unificación)". CC, 353-4 / IX, 291-2/.

29. Ib., $143-5 / I X, 157-9 /$.
} 
curre la (acción propulsiva) ejercida por "las fuerzas de transhominización)).

El aludido estado de tensión se convierte con frecuencia en un estado de (conflicto) interior, en apariencia casi irreductible. Sobre todo cuando dichas tendencias toman la forma concreta de fe cristiana y humanismo marxista, con las que, de hecho, tiende a identificárselas. De un lado, pues, la fe cen un Dios indiferente, sino hostil, a toda idea de una ultra-evolución) humana; del otro, (una fe en el Mundo, formalmente negativa (al menos verbalmente) de todo Dios trascendente). Naturalmente, se trata de un falso conflicto, tanto por el endurecimiento de ambas tendencias como porque, en el fondo, ambas (fes) están llamadas a converger y potenciarse mutuamente) ${ }^{30}$

4. Por su mismo método analítico, la ciencia moderna tiende a ignorar la existencia de Dios (cientifismo).

Tal como se ha desarrollado la ciencia moderna, puede hablarse de (cuna impotencia de la Ciencia para hallar a Dios en sus procesos analíticos). De los dos polos que tiene cada ser: (un polo inferior, del que sale; un polo superior, hacia el que asciende), el científico moderno adopta la dirección más elemental y primaria: el análisis del polo inferior.

Esta tendencia metodológica, llevada a sus extremos, ha dado lugar al (materialismo») ciencista: "quien domina los elementos posee el Todo». Este ha sido el gran sofisma. Porque, de hecho, (el materialismo nace de un error fundamental de perspectiva): persigue la realidad sólo en sus (cextremos limites inferiores, allí donde los seres están más empobrecidos y rarificados». Por eso, el análisis sólo puede darnos un aspecto - el más pobre- de la realidad. Hay que tener en cuenta la síntesis, que se realiza en el polo superior del ser, ya que (la consistencia) de los elementos (deriva de su elemento sintético), esto es, de su (espiritu», su (principio ordenador), que precisamente no puede aparecer en el análisis ${ }^{31}$.

30. $\mathrm{PH}, 323-6 / \mathrm{V}, 340-4 /$. Poco antes aseguraba a una corresponsal: "Es verdaderamente por San Pedro por donde pasa en este momento el eje ascensional (como por Moscú (?) el ejt propulsivo) de la Humanidad moderna". Carta a J. Mortier, inédita, 8 octubre 1948.

31. Ciencia y Cristo o Análisis y Sintesis (1921), CC, 43-58 / IX, 45-62 /.

En 1951, con ocasión de la Semana de Intelectuales Católicos, escribió Teilhard una nota en la que defendía su fenomenología ultrafísica: la biología, llevada a fondo, puede conducirnos a la exigencia de lo trascendente. CC, 243-4 / IX, 277-280/. Téngase en cuenta, no obstante la observación recogida en nota 28.

Las últimas páginas que escribió, Investigación, trabajo y adoración, mantienen la misma 
Despejadas, pues, las razones del gran malentendido que ha dado lugar a la incredulidad moderna, veamos ahora los principios de solución, ya implícitamente apuntados en lo expuesto.

c) Principio para una solución eficaz de la crisis.

Durante mucho tiempo han predominado, en el seno del cristianismo, planteamientos excesivamente simplistas de lo que se llama "la conversión del mundo». En primer lugar porque se enfoca como un problema de verdad y error integrales, en visión estática; luego, porque se pretende trasmitir el mensaje cristiano con todo su cargamento de adherencias históricas (mediterráneas) y encarnado en una expresión cultural de la época pre-moderna.

Teilhard de Chardin se muestra consciente de la situación desde sus primeros escritos; pero, de un modo especial, al tomar contacto con los pueblos y las civilizaciones orientales. Así escribe en 1926: (cen materia de 'conversiones', el cristianismo está en un verdadero atolladero. Visiblemente, no será por los caminos actuales como se establecerá el reino de Dios». Y postula (algún renacimiento, alguna 'revelación», que le permita difundirse en la masa humana "como el agua y como el fuego». Y apunta la solución entrevista : (me parece (...) que la chispa surgirá de la conjunción') entre Dios y el Mundo en la conciencia humana, de la que resultará la consagración de los valores humanos en Dios, "al término de un largo esfuerzo creador)" ${ }^{32}$.

$\mathrm{La}$ "conversión del mundo» la ve como un problema de asimilación y de cristianización. Pero la segunda no puede ser auténtica y eficaz sin la primera. Es cierto que el mundo no será salvado más que por lo sobrenatural, pero un sobrenatural encarnado en "la tendencia religiosa natural) de cada época ${ }^{33}$. Porque, además, "fuera de la Iglesia queda una enorme cantidad de bondad y de belleza) que debemos asimilar ${ }^{34}$. Ello afecta de lleno al problema de la incredulidad moderna :

"Ahora el problema de Dios se ofrece a la acción humana total, y sólo puede abordarse por el esfuerzo total de la búsqueda y de la experiencia humana. No sólo Dios da un valor pa-

tesis, pero puntualiza la necesidad de una educación religiosa específica para el investigador creyente, según el lema: "al cielo por la culminación de la Tierra". CC, 245-251 / IX, 281-289/.

32. Carta de 28 de abril 1926 (cit. por C. Cuénot, op. c. 185).

33. ETG, 380; CV, 96-7 / LV, $89 /$.

34. CV, 99-100 / LV, $91 \%$ 
ra siempre al esfuerzo humano, sino que, además, su revelación es una respuesta a la totalidad del esfuerzo humano" ${ }^{35}$.

Podemos formular, pues, un primer principio:

I. Principio de armonía, asimilación y conjunción Dios-Mundo.

Este planteamiento es característico de su primera época, aunque se mantiene a lo largo de su obra: "Religión y Evolución no deben ser ni confundidas ni separadas: se hallan destinadas a formar un mismo organismo continuo") y vienen a prolongarse y completarse, aunque subordinadas jerárquicamente. Se trata de lograr un (equilibrio vital, haciendo pasar toda la savia del Mundo a su esfuerzo hacia la Trinidad divinas. Lo contrario sería una triple falta de infidelidad, de presunción y de lealtad intelectual ${ }^{36}$.

El gran error del cristianismo actual consiste en su pretensión de mantener obstinadamente una expresión cultural de su mensaje que no está de acuerdo ni con el pensamiento ni con el sentimiento religioso de nuestro tiempo. De aquí el (gran escándalo» de que lo cristiano y lo Humano no coincidan ya. De aquí también que el cristianismo parezca a los ojos modernos, (invenciblemente) como algo (inhumano e inferior), o con rasgos de infantilismo ${ }^{37}$.

Sobre todo cuando se comprueba que los ideales del mundo moderno coinciden profundamente con los ideales cristianos. Esta armonía y asimilación se expresa en dos enunciados: «todo, en el Cosmos, es para el Espíritu) (ideal humano); (todo, en el Espíritu, es para Cristo» (ideal cristiano). El nombre bíblico (Emmanuel», Dioscon-nosotros, lo expresa admirablemente. En efecto, Cristo aparece (sobre la prolongación del ideal humano».

Pero es que, además, la coincidencia se convierte en "conjunción» de los dos (atractivos» o (astros), celeste y terrestre, que se realiza (en una vida plenamente humana, porque plenamente cristiana). Lo sobrenatural es lo que salva, pero encarnado en la savia na-

\footnotetext{
35. Ib., $209 / L V, 207 /$. Carta del 13 junio 1936.

36. ETG, 113-8/80-84/.

37. "En comparación con las satisfacciones y deseos que experimento ahora, la vida religiosa de otro tiempo me parece un infantilismo". Ib., 372.

Esta experiencia la registraba igualmente en numerosos cristianos: "Es increíble que $S$. $P$. se atreva a escribirme por ejemplo que EI Medio divino es un escrito para uso de algunos incrédulos, cuando yo tengo la evidencia, desde hace 20 años, que es solamente un bocado de pan, más o menos bien cocido, arrojado a la muchedumbre de cristianos que perecen de frío y de hambre en una Iglesia deshumanizada". Carta a Decizier, inédita, 6 febrero 1949.
} 
tural apropiada. De aquí que la pedagogía del cristianismo debe marcar estos tres (tiempos) :

- participar en las esperanzas y en las penas de su tiempo (esto es, (encarnarse));

- integrar esta fuerza humana en la vida sobrenatural, de modo que ambas converjan en un esfuerzo único;

- sublimar el esfuerzo humano "cristificándolo»"

Porque no podemos olvidar este hecho sintomático: los grandes (convertidores), como los grandes (perversores) de los hombres, han sido aquellos en los que ardía más intensamente el alma de su tiempo $^{39}$. Y el alma de nuestro tiempo exige un evangelio que muestra a Dios como término del más grande de los Universos, con un máximo de cooperación por parte de los hombres ${ }^{40}$.

Ya hemos visto cómo la incredulidad moderna se debe, en gran parte al menos, "(a una especie de ocultación por el 'Dios-Mundo' del 'Dios revelado'), De aquí la necesidad de una armonía y de una asimilación de ambos polos de atracción. Tanto más cuanto que no se trata de ninguna nueva forma de (irenismo", sino de una auténtica reconciliación de Dios con el mundo por coincidencia y conjunción. Sim. plemente, se rompe el malentendido por una doble operación de positivo desarrollo:

- el cristianismo recobra su dimensión cósmica y evolutiva;

- el mundo se orienta a un Omega, que coincide con Cristo.

Al mismo tiempo, ambos pierden su bagaje de adherencias históricas, que motivaban todas sus desviaciones:

- el cristianismo se desprende de su "Baianismo práctico», por el que irradia más la sombra que la luz de la Cruz;

- el Mundo se desprende de sus envolturas reaccionarias, al encontrar un Dios cristiano que viene a cumplir y consumar todos sus ideales.

Por eso puede afirmar Teilhard: (consumar es cristianizar». Porque consumar supone previamente (encarnarse». Es la única "pe-

\footnotetext{
38. ETG, 374-380.

39. Es el lema de la Nola para la Evangelización de los tiempos nuevos. Ib., 367.

40. Ib., 381. Por la misma época escribía a uno de.los Asistentes Generales de la Compañía de Jesús: "Mientras persista el escepticismo respecto de los valores humanos, estoy convencido, tras una vida de experiencias, que la fe cristiana no llegará (no puede llegar) a inflamar nuestro mundo moderno". Carta al P. Gorostarzu, inédita, 19 noviembre 1948.
} 
dagogía) a la vez eficaz y verdadera. El resto no son más que remiendos que contravienen la advertencia evangélica ${ }^{41}$.

En otro tiempo pudo ser eficaz la "pedagogía) de la (condena», cuando se trataba de (cismas) o (herejías). Ahora se trata de una nueva religión. Por eso no hay más pedagogía auténtica que la del (bautismo», ya que la nueva religión presenta, además, (un nuevo aflujo que puede reavivar el viejo fondo cristiano». Por eso, "no condenar, sino antes bien, bautizar y asimilar». Sólo así comprenderá el mundo que "la nueva divinidad que adora es precisamente el Dios cristiano más profundamente comprendido». Es el "Cristo Universal, sintesis de lo nuevo y de lo antiguo').

Porque, efectivamente, de esta conjunción puede surgir «una nueva era para el Cristianismo», que signifique (liberación interna y expansión externa). Probablemente nos hallamos ante una nueva "Epifanía), que viene a liberarnos del "ahogo y la humillación interna) y a infundirnos nueva potencia expansiva. Porque lo cierto es que el cristianismo actual (no es ya lo suficientemente contagioso».

De aquí la necesidad que tenemos de presentar a Cristo (no ya condenador, sino salvador del Mundo moderno y de sus esperanzas). Con ello el cristianismo no sólo recobrará sus dimensiones originales, sino que recobrará su poder contagioso y se difundirá (como el fuego». Pero ello nos exige (repensar, con toda nuestra humanidad, nuestra Religión». Y, en primer lugar, nos exige recobrar (cel optimismo cristiano». No bastan «los gestos» de (reconciliación». Hay que llegar decididamente a "la aceptación», olvidando de una vez "la desconfianza) que nos mueve a pensar en un (mundo senescente) y (frío), en lugar del (mundo naciente). La Iglesia tiene que amar al mundo, porque (sólo se convierte aquello que se ama). Por eso, (inmergirse para emerger y levantar». Hay que repetir el gesto histórico que dio origen al medioevo: (pasarse a los bárbaros)" ${ }^{2}$.

41. CC, $140-141 / \mathrm{IX}, 152-153 /$

42. Ib., 145-152/IX, 159-166/.

H. Gollwitzer confirma plenamente esta opinión: "La falta de fantasías de los conservadores no ha cesado de denunciar como una utopía irreal todo lo que sobrepasaba el cuadro de lo ya conocido $y$, sin embargo, somos deudores de progreso respecto de los que no han respetado los límites de lo que parecía posible para su época. Además, ¿puede estar satisfecho un cristiano de un cuadro cuyo postigo pinta al ateo como defensor de una gran esperanza para la humanidad, mientras que el otro representa al cristiano como abogado del escepticismo y el escepticismo como muro de defensa del cristianismo? Spiritus sanctus non est scepticus: esta reflexión de Lutero, ¿no debería ponernos en guardia contra semejante distribución de papeles? ¿Podemos descuidar el hecho de que la escatología atea hunde sus raices en la esperanza cristiana? ¿Puede consistir la oposición en que los cristianos abandonen el mundo a su imperfección y a su miseria en nombre de una esperanza supraterrestre, mientras que, como respuesta, los marxistas en palabras de Bebel, dejan el cielo a los ángeles y a los gorriones?". Op. cit., 127. 
2. Principio del (rebote»: "hacia lo Alto por lo hacia Adelante».

También dejé expuesto cómo, en la opinión de Teilhard, la crisis religiosa moderna adopta con frecuencia la figura de un conflicto entre lo hacia lo Alto y lo hacia Adelante", es decir, lo que tradicionalmente se ha llamado (religión) y (progreso). Sin embargo, tampoco se trata de una oposición real, sino más bien de una mutua incomprensión por la acentuación unilateral de uno de los factores.

Está claro que el proceso de evolución humana exige un punto Omega final de consumación, aunque ya actual, animador y personalizador de la socialización humana. De lo contrario nos enfrentaríamos con la "Muerte total») : es decir, un Universo "sin corazón y sin salida». Tomada en sí misma, pues, "la fe en el Mundo no basta».

Pero tampoco la fe cristiana, en su forma vigente, se basta (para levantar al Mundo hacia lo alto». El defecto radica en su incapacidad para "cristianizar lo humano». Por eso ha perdido gran parte de su poder atractivo, incluso para sus mismos fieles ("¿ por qué tanta inquietud espiritual en el corazón de los sacerdotes y de los religiosos?»). Por eso también se han detenido las conversiones: carecemos de cesa dosis sensibilizante de fe y de esperanza humanas).

Lo cierto es que, actualmente, dos fuerzas religiosas (se afrontan en el corazón de los hombres). Dos fuerzas que se combaten y se debilitan inútil y estérilmente. Cuando ambas se están necesitando mutuamente, ya que ambas se muestran incapaces de desarrollarse independientemente, mientras que se postulan desde su propia deficiencia.

Si se reflexiona sobre la negación teísta del humanismo moderno (marxistas y científicos agnósticos) se descubre que lo que niegan es, en realidad, (una forma de Dios, tipo extrínseco», esto es, rechazan un "Deus ex machina, cuya existencia rebajaría la dignidad del Universo y distendería los resortes del esfuerzo humäno»). Por tanto, un "pseudo-Dios") que nadie desea y nadie defiende, aunque el cristianismo haya dado lugar tantas veces a la confusión.

Por otra parte, la fe cristiana se enraíza en el hecho de la Encarnación, que consagra radicalmente el valor del esfuerzo humano. $Y$ se realiza esencialmente en una dimensión escatológica, hasta que halle su consumación en el (Pléroma) final. La perspectiva de la evolución hacia un (ultra-humano» encaja perfectamente con esta ver- 
tiente oscurecida del cristianismo. La Parusía necesita "física y orgánicamente) una maduración espiritual y social de la humanidad. La Tierra debe llegar "previamente al término natural de su crecimiento evolutivo». Por eso el ultrahumano que persigue el humanismo actual viene a coincidir con el ideal cristiano:

"Los dos vectores, los dos componentes (...) giran, se acercan, hasta dar una posible resultante... El hacia lo Alto cristiano se incorpora ( $\operatorname{cin}$ sumergirse en él, 'sobrenaturalizándo10') con el hacia Adelante humano. $Y$ al mismo tiempo, he aquí que la fe en Dios, en la medida en que asimila y sublima en su propia savia la savia de la fe en el Mundo, recobra su plena fuerza de seducción y de conversión".

$\mathrm{H}_{\mathrm{a}}$ llegado, pues, el momento en que «todo un pueblo de 'apátridas espirituales', seres desgarrados entre un marxismo cuya acción despersonalizante les solivianta, y un cristianismo cuya tibieza humana les descorazona), halle, al fin, la fórmula salvadora. Se abre la posibilidad de creer (al mismo tiempo y a fondo» en Dios y en el Mundo. Asistimos al nacimiento de (la Fe más fuerte, la que antes o después, acabará por poseer la Tierra». Es el (rebote») de la fe cristiana, similar al rebote de la evolución en el hombre: «el hacia lo Alto por lo hacia Adelante) ${ }^{43}$.

3. Principio del "Plus et Ego» (Evangelio del esfuerzo humano).

Ha llegado la hora del (Optimismo cristiano", la hora de que el Cristianismo (acepte por fin, sin reticencias, las nuevas dimensiones (espaciales, temporales, psicológicas) del Mundo que nos rodea) ${ }^{44}$.

De nada sirven los "gestos") aislados de una pretendida reconciliación, cuando persiste en el fondo "la misma desconfianza fundamental)». En lugar de parecer complacerse en destacar la debilidad y los fracasos del esfuerzo humano, la Iglesia debería adoptar decididamente la actitud paulina: "Sois hombres? Plus et Ego»"

Es preciso comenzar por sincerarnos plenamente. Mientras sigamos sintiéndonos incómodos entre las aspiraciones y las esperanzas del humanismo actual, nada sólido y eficaz podremos conseguir. Porque (sólo se convierte aquello que se ama). El Cristianismo tiene que

43. El corazón del problema (1949), $\mathrm{PH}, 326-332 / \mathrm{V}, 343-9 /$.

"¿Dónde va el mundo religiosamente? Respondo: 1.0 , hacia una fe más grande; $2 .^{\circ}$, diferente de todas las formuladas; 3.0 , sintesis en formación de la fuerza ascensional crística (hacia un Personal trascendente) y la fuerza propulsiva moderna hacia adelante (hacia un Colectivo inmanente)". Carta a M. A. Cusenier, inédita, 11 agosto 1948.

44. CC, $151 / I X, 165 \%$. Cfr. nota 28.

45. MD, 59 /IV, $62 / ; \mathrm{CC}, 148 / \mathrm{IX}, 162$ /; Ib., 249 /IX, 287/. 
simpatizar con el mundo que nace. Ello no es posible (si no experimenta en su interior las aspiraciones y las ansiedades del mundo moderno». "Cristificar" significa "inmergirse para emerger y para levantar». Es la ley misma de la Encarnación. ¿Por qué no repetir el gesto histórico de los Papas, hace más de mil años, cuando se decidieron a "decir adiós al Mundo romano» y "pasarse a los bárbaros»? "6

Hoy se está esperando una palabra, un gesto similar y más profundo: (incorporar el progreso del mundo en nuestras perspectivas del Reino de Dios. Incorporar el sentido de la Tierra, el sentido humano, en la Caridad". Es la esperada conjunción -mutuamente potenciadora- de los dos astros que dominan nuestro cielo y nuestro corazón, provocando una peligrosa (esquizofrenia religiosa).

Esta es "la palabra esperada), la solución consciente o inconscientemente deseada en lo más profundo del alma moderna. El cristianismo no puede defraudar. Aparte de que se juega la supervivencia en la empresa. Aparte que con ello se abriría una nueva era de liberación interna y de expansión exterior. Porque es, ante todo, un deber de autofidelidad y autodesarrollo: la síntesis deseada de lo más tradicional y lo más nuevo en el seno del mensaje evangélico:

- el Cristo-Universal, consumador y salvador de lo humano.

- el Cristo-Omega, "Meta inmensa, concreta y segura".

- la cruz, símbolo de expiación, pero también "signo del crecimiento a través del esfuerzo".

- el "Evangelio de conquista humana" sobre la mansedumbre y la dulzura.

- la Caridad, no sólo como "aceite que suaviza", sino también como resorte de trabajo e investigación: "Plus et ego"... ${ }^{47}$.

No basta "la santificación del esfuerzo humano» (en virtud de la Encarnación, (nada es profano»), sino que es precisa "la humanización del esfuerzo cristiano», esto es, la promulgación del (Evangelio del esfuerzo humano's. La gran sospecha - ya lo sabemos- que hace impermeables a los hombres de nuestro tiempo ante el mensaje cristiano es de que el Cristianismo (hace a sus fieles inhumanos). En efecto, el cristianismo actual ofrece una apariencia de (inferioridad), de (ffatiga), de (escepticismo».

46. CC 151-2 / IX 165-6/. El primer subrayado es mío.

47. Cahiers 4, 25-29; CC, 147-152/IX, 161-6/; ETG, 75-87 / 47-57/. 
Por eso se hace urgente la puesta en acción de una auténtica pedagogía del "Más yo», la única que puede persuadir a los hombres de que no somos "desertores y falsos hermanos), que nuestra fe cristiana no nos (minoriza) ni nos (falsea), ni nos (aisla) de la gran corriente humana.

Precisamente nosotros, para quienes resulta una "cuestión de vida o muerte que la Tierra triunfe aún en sus fuerzas más naturales». Para nosotros, en efecto, se trata de (la compleción y del triunfo del mismo Dios). Si a veces hemos dado la impresión de desentendernos del esfuerzo humano, "no debéis criticar más que nuestra propia debilidad). Porque, "en nombre de nuestra fe, tenemos el derecho y el deber de apasionarnos por las cosas de la Tierra). Tenemos el sagra. do deber de la Investigación. Debemos intentar, para ello, "todos los caminos). Dios lo quiere, (puesto que ha querido necesitarlo. ¿'Sois hombres? Plus et Ego).

Efectivamente, "Dios encarnado no ha venido a disminuir en nosotros la responsabilidad magnífica ni la espléndida ambición de hacernos nosotros mismos) ((non minuit, sed sacravit)). ${ }^{48}$.

Es la gran hora y la gran responsabilidad del cristianismo. ¿Sabremos ser fieles a Dios y al Mundo? Aquí radica, verdaderamente, (el corazón del problema» en el momento actual de la humanidad.

Jose Rubio CarRacedo

48. MD, 57-60 / IV, 59-62/. 
* Este trabajo es un capítulo de la obra titulada: La trasposición del cristianismo en Teilhard de Chardin (de próxima aparición).

Utilizo las siguientes siglas:

TC: Teilhard de Chardin.

PTC: Pierre Teilhard de Chardin.

I: Le Phénomène humain (Ed. du Seuil, Paris, 1955).

II: L'Apparition de l'Homme (Ib. 1956).

III: La Vision au Passé (ib., 1957).

IV: Le Milieu Divin (ib., 1957).

V: L'Avenir de l'Homme (ib., 1959).

VI: L'Energie humaine (ib., 1962).

VII: L'Activation de l'énergie (ib., 1963).

VIII: La Place de l'Homme dans la Nature (ib., 1965).

IX: Science et Christ (ib., 1965).

$\mathrm{X}$ : Comment je crois (ib., 1969).

GZH: El grupo zoológico humano (Ed. Taurus. Madrid, 1957).

AH: La aparición del hombre (ib., 1958).

VP: La visión del pasado (ib., 1958).

FH: El fenómeno humano (ib., 1963).

$\mathrm{EH}$ : La energía humana (ib., 1963).

$\mathrm{AE}$ : La activación de la energía (ib., 1965).

CC: Ciencia y Cristo (ib., 1968).

CYC: Como yo creo (ib., 1970).

GP: Génesis de un pensamiento (ib., 1963).

Genèse d'une pensée (Grasset, París 1961).

ETG: Escritos del tiempo de la guerra (Taurus, 1966).

Ecrits au temps de la guerre (Grasset, 1965).

LV: Lettres de voyage (ib., 1961).

CV: Cartas de viaje (Taurus, 1957).

NCV: Nuevas cartas de viaje (ib., 1960).

LLZ: Lettres à Lèontine Zanta (Ed. Desclée de Br., París 1965).

ALH: Accomplir l'Homme (Ed. Grasset, Paris 1968).

Cahiers 4: La parole à Herder (Ed. du Seuil, París 1963). 